\title{
GEOVISUALIZAÇÃO DA ARBORIZAÇÃO VIÁRIA PATRIMONIADA DA ZONA CENTRAL DE SETE LAGOAS-MG
}

\author{
GEOVISUALIZATION OF HERITAGE STREET TREES IN THE CENTRAL ZONE OF \\ SETE LAGOAS-MG
}

Jussara Kele da Silva ${ }^{1}$, Matheus Pereira Libório², Sandro Laudares ${ }^{3}$

\section{RESUMO}

A gestão pública eficiente da arborização urbana, e consequentemente, sua manutenção e preservação, gera benefícios econômicos, ambientais e sociais à população. No entanto, a importância da conservação da arborização urbana nem sempre é plenamente reconhecida, explorada e difundida. A falta de diagnóstico, valorização ou monitoramento pode levar a ações inadvertidas ou irresponsáveis com consequências danosas e irreparáveis, bem como dificulta a gestão pública. Neste contexto, esta pesquisa objetivou difundir conhecimentos relacionados à arborização viária patrimoniada da zona central de Sete Lagoas-MG, isto é, as árvores que possuem leis ou decretos municipais específicos que as protegem, imunizando-as de corte. Para isso, um protótipo de geovisualização na web foi desenvolvido e publicado na internet. O protótipo reúne um conjunto de dados estruturados, organizados e acessíveis via código de resposta rápida, compartilhando informações, inclusive o valor estimado da arborização urbana patrimoniada. Além disso, uma ferramenta de geocolaboração foi disponibilizada para troca de conhecimentos e informações com a população, bem como funções para pesquisas e melhor caminho, permitindo aos gestores públicos planejarem ações para gestão eficiente da arborização urbana patrimoniada.

Palavras-chave: Arborização urbana; Geovisualização; Código de resposta rápida.

\section{ABSTRACT}

The efficient public management of urban trees and consequently its maintenance and preservation, generates economic, environmental and social benefits to the population. However, the importance of conservation of urban trees is not always fully recognized, exploited and disseminated. The lack of diagnosis, valorization or monitoring of urban forest can lead to inadvertent or irresponsible actions with harmful and irreparable consequences and also complicates public management. In this context, this research aimed to disseminate knowledge related to heritage street afforestation at the central area of Sete Lagoas, Minas Gerais, in other words, trees that have laws or specific local ordinances that protect them by preventing from cutting. In order to do this, a geovisualization web prototype was developed and published on the Internet. The prototype brings together a set of structured data organized and accessible via quick response code, sharing information, including the estimated value of heritage urban trees. Thus, a geocolaborative tool was presented to exchange knowledge and information with interested public as well as functions to search and generate better paths, allowing public managers to plan actions for efficient management of heritage urban trees.

Keywords: Urban trees; Geovisualization; Quick response code.

Recebido em 24.06.2016 e aceito em 19.09.2016

1 Geógrafa, Especialista do Programa de Pós-graduação em Geoprocessamento da PUC Minas Virtual, Belo Horizonte/MG. Email: ju7lagos@yahoo.com.br

2 Economista e administrador, Msc., Coordenador Adjunto do Programa de Pós Graduação em Geoprocessamento da PUC Minas Virtual, Belo Horizonte/MG. E-mail: m4th32s@gmail.com

3 Analista de Sistemas, Dr., Professor do Departamento de Geografia da PUC Minas, Belo Horizonte/MG. E-mail: sandrolaudares@gmail.com 


\section{INTRODUÇÃO}

As relações sociais desenvolvidas nos centros urbanos interagem com os elementos naturais que compõem esses espaços. A arborização urbana é, para Bonametti (2001), o reflexo da relação entre o homem e a natureza, pois o modo como é projetada e construída reflete o grau cultural da sociedade, representado costumes, acontecimentos e fatos históricos, com aspectos naturais, agregando valor à paisagem. Por isso, Seamans (2013) afirma que a arborização urbana se transformou, nas últimas décadas, num serviço ambiental e social relevante, muito além de um papel típico de embelezamento ou ornamentação, amparado no planejamento urbano e nas políticas públicas.

Nesse contexto, Basso e Corrêa (2014) ressaltam a importância do planejamento na preservação, manutenção e melhoria da arborização urbana, contribuindo para a conservação da paisagem e para o conforto ambiental nos espaços livres da cidade. Assim, Quissindo, Oconor e Luna (2016) afirmam que o conhecimento da constituição arbórea favorece a adequação das espécies às condições urbanas e, consequentemente, reduz custos de manutenção. Dessa forma, Basso e Corrêa (2014) enfatizam que adequação das espécies às condições urbanas cria um ambiente que integra expectativas e qualidade de vida com a arborização urbana. Adicionalmente, Batista e Barbosa (2014) afirmam existirem plantas nativas para todos os tipos de ambientes e solos, sendo fundamental respeitar a aptidão ambiental de cada espécie, evitando danos à circunvizinhança. Para reduzir a ocorrência desses danos ou conflitos, Meira et al. (2016) afirmam que se deve mapear o quadro existente, diagnosticando incompatibilidades.

O planejamento da preservação ou da manutenção da arborização urbana exige, previamente, como mostram os trabalhos de Benatti (2012), Souza et al. (2011) e Quissindo, Oconor e Luna (2016), a elaboração da situação reinante para identificar, mapear, divulgar, cuidar e manter o patrimônio arbóreo existente. Para Meira et al. (2016), a informatização e a geotecnologia são promotoras da eficácia do planejamento da preservação e da manutenção da arborização urbana, pois reduzem a ocorrência de incompatibilidades, danos e conflitos.

A arborização urbana, no seu caráter multifuncional e multidisciplinar, é definida por Konijnendijk et al. (2006) como a habilidade, ciência e tecnologia de gestão de árvores e recursos florestais do meio urbano, trazendo benefícios sociológicos, econômicos e estéticos para a sociedade. Na definição de Benatti (2012), a arborização urbana é um conjunto de elementos vegetais de porte arbóreo, situado no perímetro da cidade, inclusive em calçadas.

De modo amplo, a arborização urbana apresenta benefícios que transcendem uma avaliação superficial dos produtos ambientais gerados como mostram Seamans (2013), Young (2010) e Roy, Byrne e Pickering (2012), consistindo, sobretudo, na oferta de serviços 
ambientais como conforto acústico, abrigo da fauna urbana, aumento das áreas permeáveis, valorização econômica dos espaços e amenização do microclima, beneficiando indistintamente a coletividade.

A amenização do microclima, conforme Martini et al. (2016), é um benefício que contribui para a redução da temperatura e o aumento da umidade relativa do ar nos espaços com arborização urbana. Ademais, Pataki et al. (2011) destacam outros serviços fornecidos pela arborização urbana, dentre eles a redução da poluição do ar, o armazenamento de carbono, a melhoria da qualidade da água, a redução do consumo de energia e o controle de águas pluviais.

Além dos benefícios ecológicos, Seamans (2013) destaca que a arborização urbana produz benefícios sociais relacionados à melhoria do bem estar, à produtividade no trabalho, ao tempo de recuperação de pacientes hospitalizados e ao desenvolvimento da criança.

Por isso, Grande Ortiz, Ayuga Téllez e Contato-Carol (2012) mostram várias metodologias que procuram monetizar os benefícios da arborização urbana, e assim influenciar - gestor público a exercer uma melhor administração dessa arborização. A escolha metodológica está, conforme Grande Ortiz, Ayuga Téllez e Contato-Carol (2012), relacionada à disponibilidade de dados, e por este motivo, que se utilizou o método paramétrico de Kane e Kirwan (2009) para estimar o valor da arborização urbana escolhida na presente pesquisa.

A arborização urbana é, conforme Ordóñez e Duinker (2014), parte integrante do meio urbano e fator atuante na qualidade de vida de uma população. O valor ecológico e a representatividade histórico-cultural da arborização urbana retrata sua importância, tornando necessária protegê-la através de leis e decretos, imunizando-a de corte, tornando-a patrimoniada. Portanto, uma arborização é patrimoniada quando leis ou decretos municipais específicos a proteja, imunizando-a de corte, tornando-a um patrimônio coletivo.

No município de Sete Lagoas, a Lei 6.704 estabelece quais são os exemplares arbóreos imunes de corte, sendo o decreto 589 o instrumento que destaca a importância e o valor desses exemplares, caracterizando-os conforme suas condições de beleza, antiguidade, raridade e porta sementes (SETE LAGOAS, 2016). Esse mesmo decreto declara obrigatório afixar placas indicando: o nome vulgar e científico da árvore, a sua proibição de corte e a exigência de autorização prévia e expressa da autoridade competente para coleta de sementes.

As árvores são consideradas por Batista e Barbosa (2014) como riquezas naturais e por isso a indicação das informações sobre as mesmas deve ser acessível a todos os cidadãos. A democratização do conhecimento incentiva a atitude proativa e cidadã com as árvores dos espaços viários, em especial a arborização viária patrimoniada, todavia, no cenário discutido, não se encontra instrução formal, isto é, material que direcione tal ação. 
Por isso, Gaston, Ávila-Jiménez e Edmondson (2013) reforçam a importância da organização das informações da arborização viária em sistemas computadorizados, integrando registros e informações do patrimônio local e proporcionando o conhecimento holístico sobre o espaço observado. Nesse contexto, os autores destacam a importância da associação de dados espaciais com dados alfanuméricos, através das tecnologias de geoprocessamento.

O geoprocessamento é, conforme Laudares (2014), um agregado de tecnologias para a coleta e o tratamento de dados geográficos, objetivando a localização, a distribuição e a análise espacial de atributos, alcançando a todos. Na perspectiva do desenvolvimento sustentável, de Kirnbauer et al. (2009), a integração entre desenvolvimento econômico e preservação ambiental permeia uma infraestrutura sólida de partilha e promoção do conhecimento sendo a geovisualização um relevante meio de difusão de informação.

A geovisualização é definida por Lorenzi et al. (2014) como um processo de criação e manipulação de mapas e seus conjuntos de dados de modo associado, sendo para Bowie, Millward e Bhagat (2014) uma ferramenta útil e apropriada para fazer descobertas e formular hipóteses, pois é uma técnica de análise de reconhecimento de padrões em ambientes computacionais interativos.

Um sistema de geovisualização de baixo custo de implantação é o WebGIS, que conforme Chow (2008), permite o desenvolvimento de aplicações através das interfaces de programação de aplicações, ou Application Programming Interface (API) do Google Maps para realizar consultas visuais e manipular informações geográficas (vetoriais e raster) de forma rápida em interfaces dinâmicas. O compartilhamento do conhecimento através do WebGIS, afirma Laudares (2014), possibilita a descentralização do poder, alimentando o sentimento de pertencimento e ação cidadã participativa, fortalecendo a participação da população na gestão pública. A produção de material voltado à identificação da arborização viária patrimoniada permite, no mínimo, fortalecer o cidadão através de uma fiscalização multiparticipativa e efetiva do patrimônio conhecido.

Neste cenário, um conjunto de conhecimentos sobre a arborização viária patrimoniada da área central de Sete Lagoas-MG foi sistematizado em um protótipo de geovisualização e compartilhado na internet, possibilitando a interação da sociedade com o ambiente.

\section{MATERIAL E MÉTODOS}

Este artigo apresenta uma pesquisa experimental, onde um protótipo de geovisualização foi desenvolvido para visualizar e difundir conhecimentos sobre a arborização viária patrimoniada da região central de Sete Lagoas, em Minas Gerais. O protótipo oferece 
informações sobre a arborização imune de corte, protegida por leis ou decretos municipais, de forma interativa e colaborativa.

\section{Área de estudo}

A Zona Z7, região central da cidade de Sete Lagoas-MG, município com $538 \mathrm{~km}^{2}$ de área (ver Figura 1), é um espaço geográfico definido na Lei de Uso e Ocupação do Solo, Decreto $n^{\circ} 1.960$, caracterizada por sua importância histórica, intensa atividade urbana e grande fluxo de pessoas é região foco desse estudo (SETE LAGOAS, 2016).

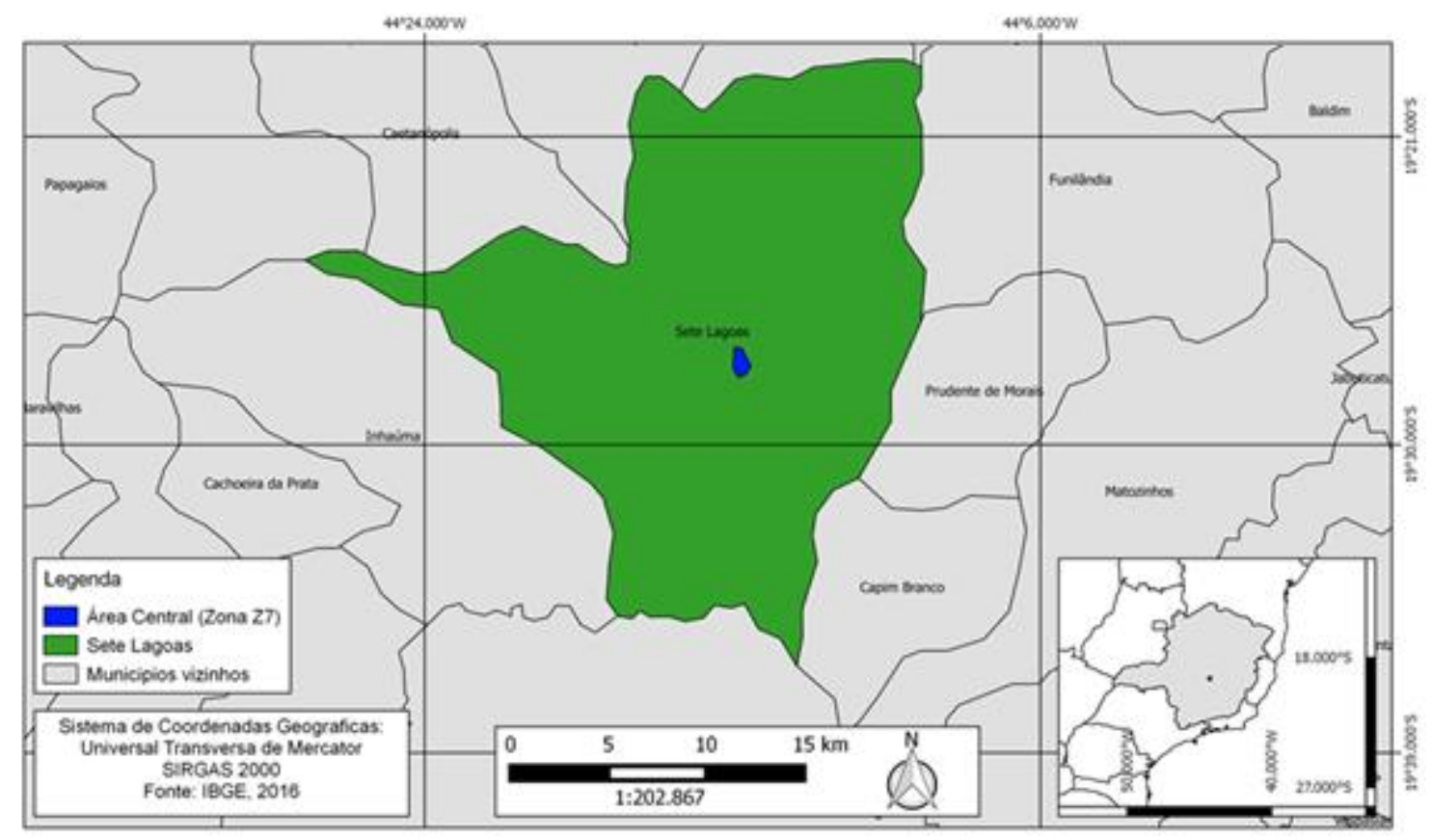

Figura 1. Mapa de Localização da cidade de Sete Lagoa-MG

Figure 1. Location map of Sete Lagoas-MG

De acordo com IBGE (2016) a população estimada para a cidade de Sete Lagoas em 2016 em é de 234.221 habitantes. O clima é caracterizado como tropical chuvoso, do tipo Aw, com invernos secos e chuvas máximas no verão. A precipitação média anual dá-se entre 1.100 e $1.450 \mathrm{~mm}$. A temperatura média anual é de 22,9 graus célsius. A característica fisionômica principal é a vegetação de cerrado, se sua a bacia hidrográfica é a do Rio São Francisco, subbacia do Ribeirão Jequitibá, contribuinte da margem esquerda do Rio das Velhas.

\section{Etapas da pesquisa}

O ambiente de desenvolvimento protótipo de Geovisualização da Arborização Viária Patrimoniada foi composto por aplicações e softwares, sendo as etapas necessárias para o seu desenvolvimento sintetizadas na Figura 2 e detalhadas em sequência. 


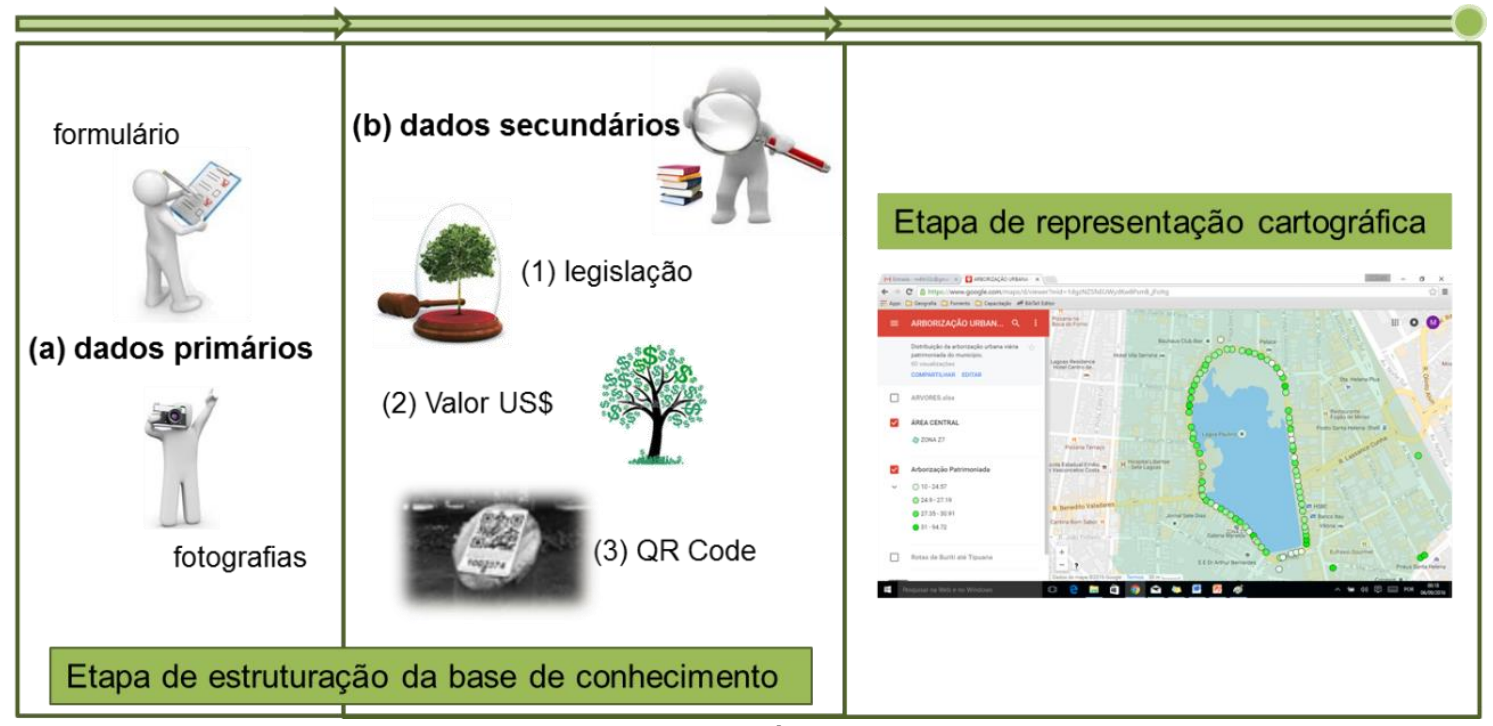

Figura 2. Metodologia para o desenvolvimento do protótipo de geovisualização

Figure 2. Methodology of geovisualization prototype development

A etapa de estruturação da base de conhecimento da arborização viária patrimoniada foi subdividida nos passos (a) coleta de dados primários e (b) coleta de dados secundários.

Os dados primários, incluindo registros fotográficos, foram coletados e catalogados observando a metodologia utilizada por Souza et al. (2011) em visitas de campo. A Tabela 1 reproduz o formulário de inspeção de campo, resumindo o conjunto de dados primários.

Tabela 1. Formulário de inspeção de campo

Table 1. Field inspection form

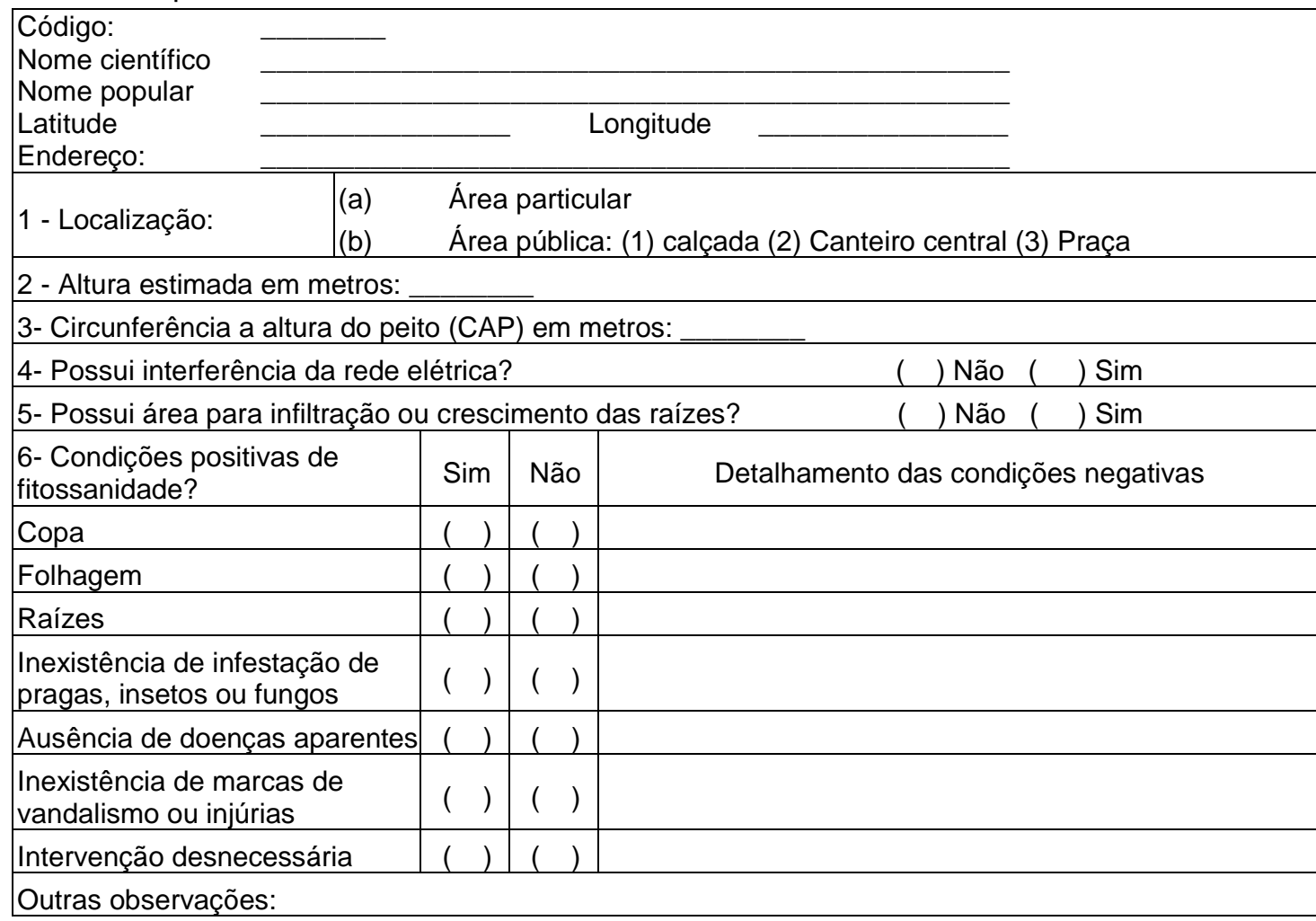


Os dados secundários foram obtidos, por sua vez, em três fases. Na fase (1), os dados de endereço e legislação municipal correlata foram coletados na Secretaria Municipal de Meio Ambiente e Sustentabilidade da prefeitura de Sete Lagoas-MG. Na fase (2), o dado do benefício gerado por árvore (US\$ / ano) foi calculado através da metodologia de Kane e Kirwan (2009), método pelo qual o valor da árvore é o produto da circunferência a altura do peito (CAP) por parâmetros relacionados a benefícios citados por Pataki et al. (2011) como absorção de carbono, economia de energia, redução da poluição e economias relacionadas às redes de drenagem.

Em detalhe, Kane e Kirwan (2009) mostram que as árvores absorvem carbono durante seu período de crescimento, pelo acumulo da biomassa, reduzindo assim o efeito estufa. A economia de energia ocorre pela amenização do clima, consequência do processo de transpiração da água a partir das folhas das árvores, arrefecendo o clima na atmosfera. A redução da poluição do ar é um efeito gerado pela retenção de partículas nas copas das árvores, que absorvem a poluição através das folhas, que posteriormente são lavadas para o solo após as chuvas, onde são eliminadas por micróbios. As economias relacionadas às redes de drenagem ocorrem quando as árvores interceptam grandes quantidades de chuva, o que reduz a quantidade de escoamento em correntes e rios, estendendo o tempo de absorção da chuva pela micro-bacia, reduzindo a erosão e as inundações. O cálculo destes benefícios foi baseado nas equações e parâmetros abaixo:

1. Absorção de carbono $=0,027$ * $(\mathrm{CAP})^{2}-0.095 *(\mathrm{CAP})+6,85$;

2. Economia de energia $=\$ 4(\mathrm{CAP}<8), \$ 7,50(\mathrm{CAP}<20)$ e $\$ 8,50(\mathrm{CAP}>21)$;

3. Redução da poluição $=0,16$ * $(\mathrm{CAP})^{2}-0,334$ * $(\mathrm{CAP})+2,57$;

4. Drenagem $=0,0303 *(C A P)^{2}+0,182 *(C A P)+2,29$.

$\mathrm{Na}$ fase (3) foi gerado o código de resposta rápida (Quick Response Code - QR Code), que, conforme Lorenzi et al. (2014), facilita a geovisualização e a interação de informações através de dispositivos móveis na web, permitindo ao cidadão de Sete Lagoas identificar e compartilhar informações sobre a arborização viária patrimoniada da Zona Z7 da cidade.

Assim, os dados foram estruturados em planilha do software Microsoft Excel, sendo geocodificados pelo endereço no aplicativo My Maps da Google, extraindo assim as coordenadas geográficas pelos centroides $X$ e $Y$ dos pontos. A síntese dos dados que compõem o protótipo é apresentada na tabela 2. 
Tabela 2. Estrutura de dados do protótipo

Table 2. Prototype data structure

\begin{tabular}{|c|c|c|}
\hline Tipo & Informação & Descrição da informação coletada \\
\hline \multirow{5}{*}{ Dados primários } & Referências & $\begin{array}{l}\text { Código de identificação, nome científico e nome } \\
\text { popular. }\end{array}$ \\
\hline & Localização & $\begin{array}{l}\text { Coordenada geográfica, endereço e local urbano } \\
\text { (área particular ou pública, calçada, canteiro ou } \\
\text { praça). }\end{array}$ \\
\hline & Características & $\begin{array}{l}\text { Altura estimada, formato da copa e circunferência } \\
\text { do tronco. }\end{array}$ \\
\hline & $\begin{array}{l}\text { Entorno e } \\
\text { Infraestrutura }\end{array}$ & $\begin{array}{l}\text { Detalhamento da presença da rede elétrica e sua } \\
\text { interferência, detalhamento da área de infiltração e } \\
\text { detalhamento da área de crescimento das raízes. }\end{array}$ \\
\hline & Aspectos sanitários & $\begin{array}{l}\text { Descrição das condições de fitossanidade, } \\
\text { presença de pragas, presença de doenças, injurias } \\
\text { ou marcas de podas e aspecto das folhas, flores, } \\
\text { sementes, raízes e tronco. }\end{array}$ \\
\hline \multirow{4}{*}{$\begin{array}{l}\text { Dados } \\
\text { secundários }\end{array}$} & $\begin{array}{l}\text { Legislação } \\
\text { correlata }\end{array}$ & $\begin{array}{l}\text { Especificação do ordenamento jurídico e } \\
\text { informações sobre a imunidade do espécime } \\
\text { arbóreo ao corte. }\end{array}$ \\
\hline & Endereço & Tipo, nome e número do logradouro mais próximo. \\
\hline & $\begin{array}{l}\text { Benefícios } \\
\text { (US\$/ano) }\end{array}$ & $\begin{array}{l}\text { Benefício gerado por cada árvore em dólares por } \\
\text { ano conforme método de Kane e Kirwan (2009). }\end{array}$ \\
\hline & QR Code & Código de resposta rápida \\
\hline
\end{tabular}

$\mathrm{Na}$ etapa de representação cartográfica, os elementos da interface de geovisualização do mapa foram definidos. Assim, os registros fotográficos, a camada da Zona Z7, o QR Code, bem como as ferramentas de busca e traçado de rota foram disponibilizadas no protótipo através da internet*

\section{RESULTADOS E DISCUSSÕES}

Na tela inicial do protótipo, apresentada na Figura 3, visualiza-se a área de estudo Z7 com sua respectiva arborização viária patrimoniada representada por pontos verdes, os quais estão associados ao registro fotográfico e às informações apresentadas na tabela 2. No protótipo, cada árvore patrimoniada é simbolizada por um ponto em tom de verde, representando o intervalo do valor do benefício que cada árvore é capaz de gerar. Para definir os intervalos de cor se aplicou o método quantil, distribuindo as os intervalos de modo que todos tivessem o mesmo número de observações.

\footnotetext{
* GOOGLE, Google My Maps. Protótipo de Geovisualização da Arborização Viária Patrimoniada da Zona Central de Sete Lagoas-MG. Google My Maps. Disponível em: <https://www.google.com/maps/d/viewer?mid=1dgzNZSfsEUWydKw8PsmB_ jFoltg >. Acesso em 05 fev. 2016.
} 


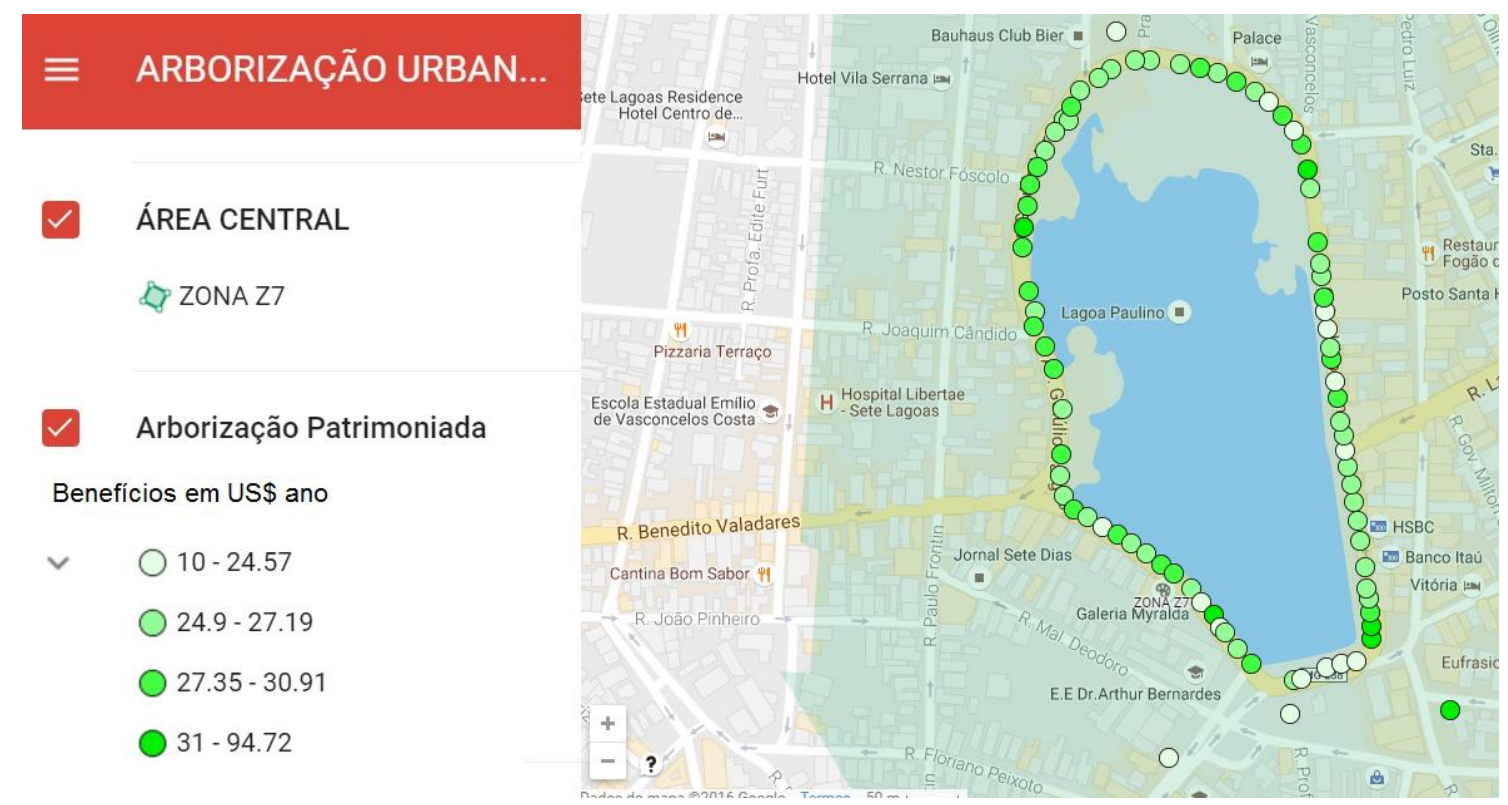

Figura 3. Tela inicial do protótipo de geovisualização

Figure 3. Geovisualization prototype front page

O protótipo permite utilizar funções como a visualização de imagem de satélite, a localização de pontos de interesse, a indicação do melhor caminho entre pontos e a geovisualização das informações da arborização viária patrimoniada.

Para a localização de um ponto de interesse digita-se, por exemplo, Caesalpinia ferrea Mart. ex. Tul var. leiostachya Benth (Pau Ferro) no campo de busca, representado por uma lupa. O protótipo retornará todas as árvores Pau-ferro, da Zona Z7 de Sete Lagoas, seu respectivo endereço e seu posicionamento no mapa, cabendo ao usuário escolher um dos registros para acessar as informações detalhadas, com sua respectiva fotografia, como mostra a Figura 4. Neste exemplo, se observou a ocorrência de danos à calçada, limitação do espaço para infiltração, problemas na base do tronco, inclinação da copa em função de podas anteriores, além da existência de rede elétrica.

Dessa Forma, o protótipo permite que a população e o administrador público monitorem as condições da arborização viária patrimoniada, confrontando as informações registradas em campo com novas informações, pois como mostraram Saarinen et al.(2014) as condições da arborização urbana variam ao longo do tempo. Os autores reafirmaram a necessidade da atualização das informações sobre a arborização urbana, se utilizando da tecnologia de varredura a laser para atualizar informações como a altura da árvore, circunferência a altura do peito e dimensão da copa. A importância das informações sobre a arborização urbana para ações de planejamento foi abordada por Souza et al. (2011), que mostraram a relevância dos dados sobre a arborização para ações de planejamento em 
Aracaju-SE. Neste estudo os dados foram coletados por um censo entre setembro de 2006 e julho de 2007.

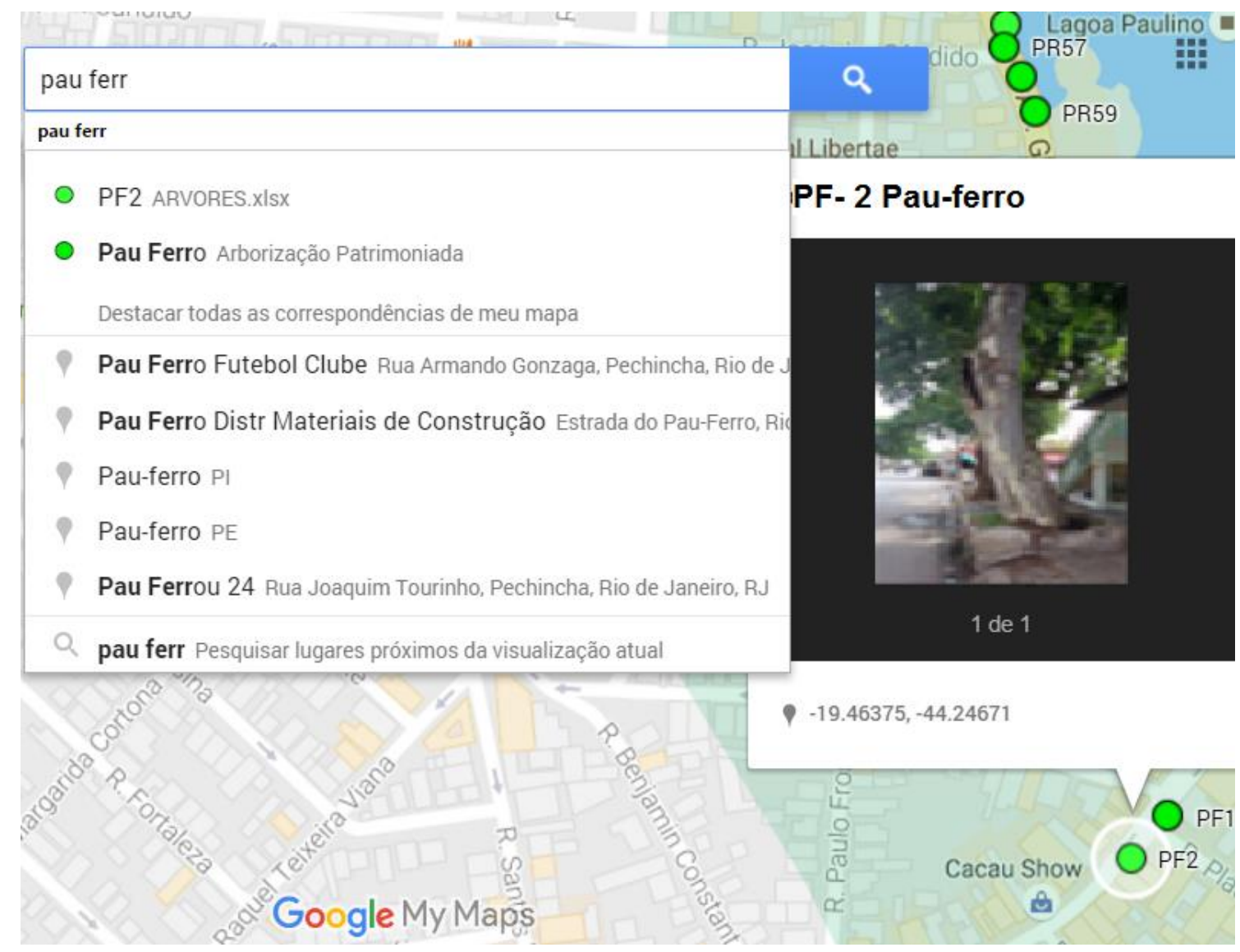

Figura 4. Apresentação dos resultados após pesquisa por "Pau Ferro"

Figure 4. Results presentation after searching for "Pau Ferro"

Ao contrário dos trabalhos de Saarinen et al.(2014) e Souza et al. (2011), o protótipo é interativo, permitindo que o usuário agregue conhecimentos e mantenha as informações atualizadas, contribuindo para aperfeiçoar ações de planejamento da arborização urbana, tomar decisões racionais e sustentáveis, estando disponível para ser utilizado ou aplicado, convenientemente, na prática do órgão ambiental municipal. Os gestores municipais poderão utilizar a ferramenta para se precaver e prevenir atos que são de sua competência exclusiva.

Além disso, o protótipo também dispõe de uma ferramenta capaz de determinar o melhor caminho entre dois pontos de interesse, favorecendo ações de manutenção da arborização pelo poder público, ação pela qual, Basso e Corrêa (2014) afirmam ser uma forma de conservar a paisagem e o conforto ambiental dos espaços livres da cidade, ademais, conforme Quissindo, Oconor e Luna (2016), permite reduzir custos de manutenção, uma vez que o conhecimento da arborização urbana está disponível. 
Por exemplo, caso uma equipe de manutenção tenha realizado uma tarefa no local da Mauritia flexuosa L.f. (Buriti) - Ponto A e precisa se deslocar até o local Tipuana tipu (Benth) Kuntze (Tipuana) - Ponto B, a ferramenta do melhor caminho indicará no mapa o trajeto de deslocamento mais curto para esta equipe, como mostra a Figura 5.

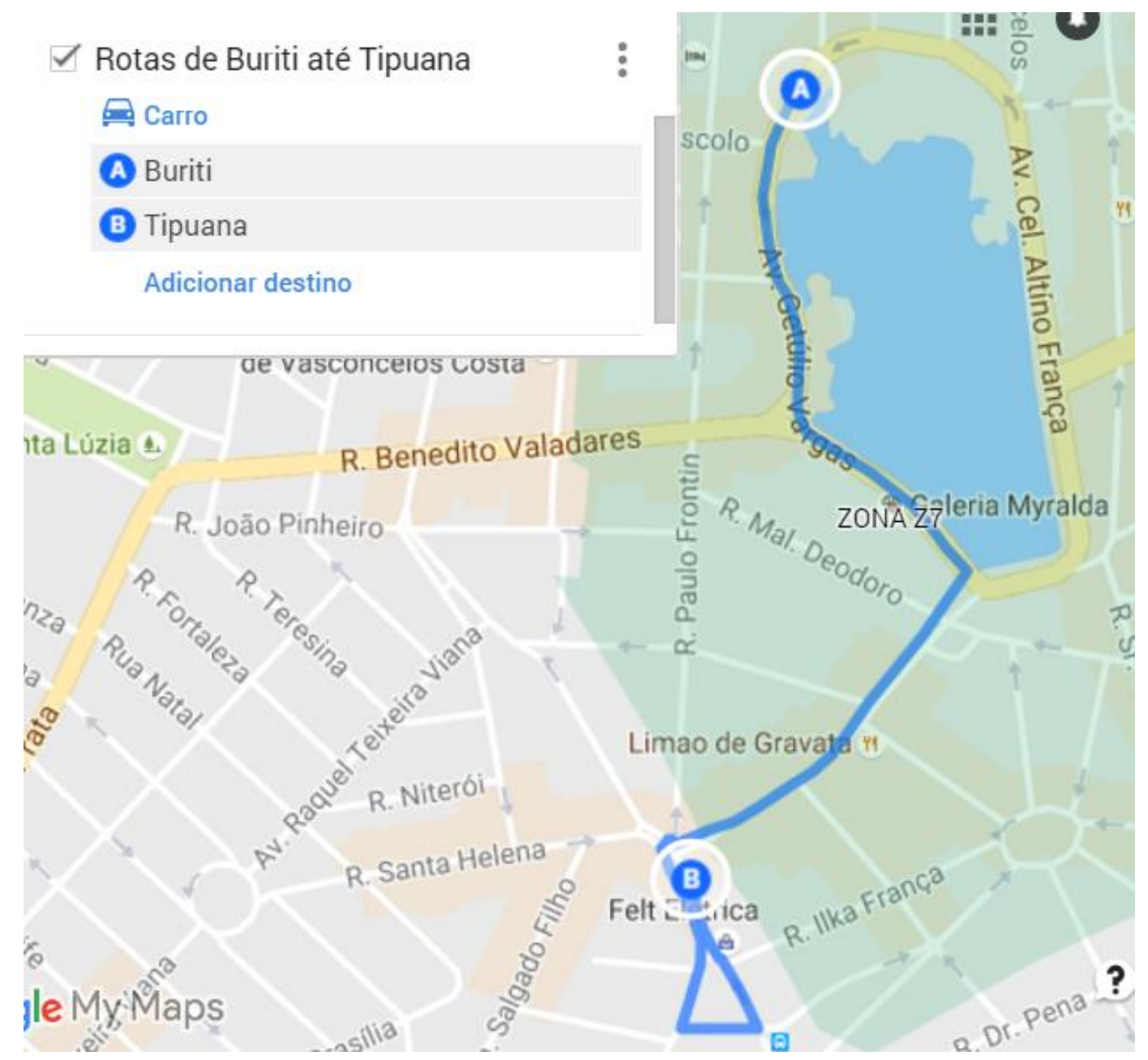

Figura 5. Rota entre árvores patrimoniadas escolhidas: Tipuana (A) e Buriti (B)

Figure 5. Route between chosen heritage trees: Tipuana (A) and Buriti (B)

Para solucionar a falta de identificação das árvores viárias patrimoniadas da Zona Z7, exceção em apenas 2 árvores, associou-se um $Q R$ Code a cada registro (árvore), permitindo o acesso rápido, fácil e universal às informações, além da possibilidade da interatividade e usos múltiplos contidos no protótipo pelo cidadão. A Figura 6 representa um recorte do banco de dados, mostrando parte das informações e o mapa, após uma consulta feita pelo usuário através do $Q R$ Code. 


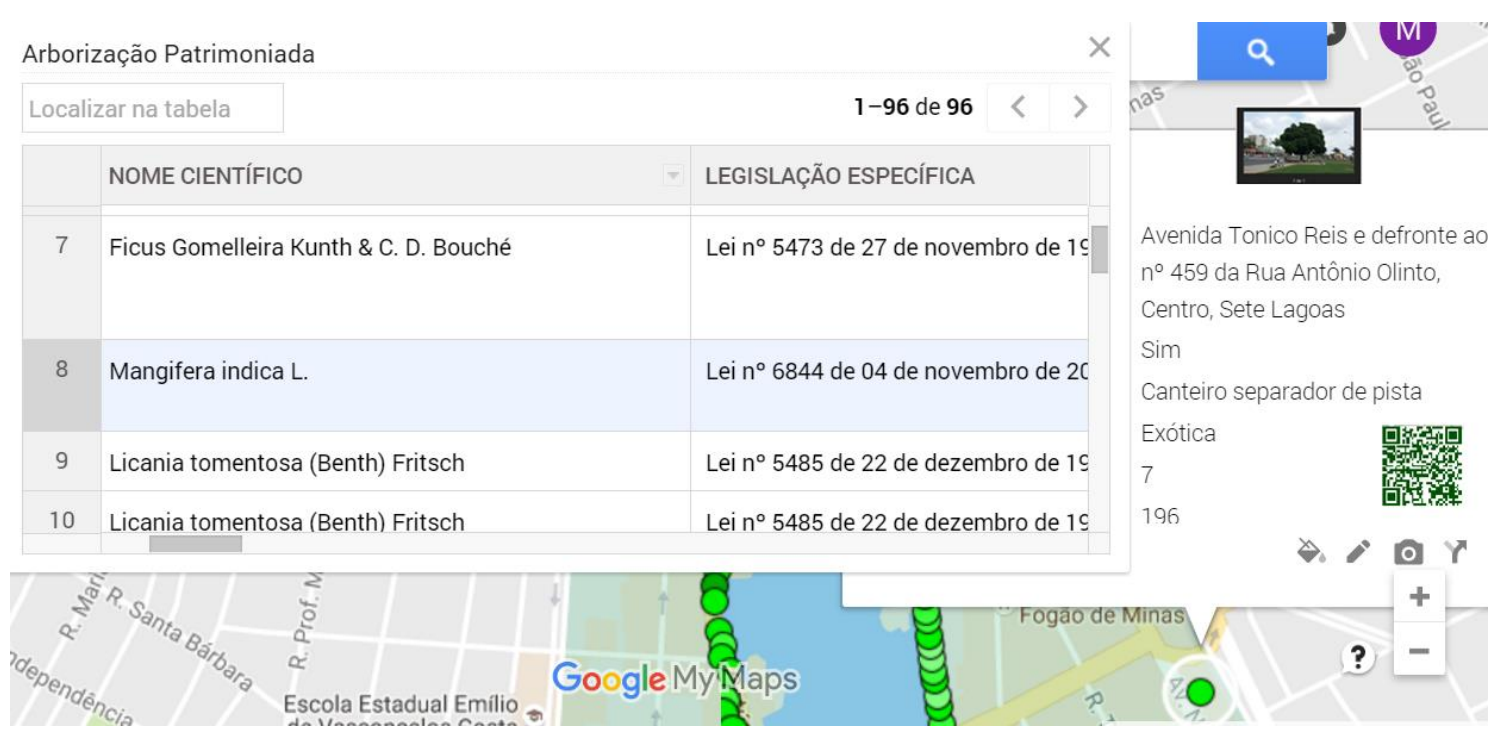

Figura 6. Representação do $Q R$ Code de registro do banco de dados: "Mangueira" Figure 6. $Q R$ Code representation of specific database record: "Mangueira"

A função de identificação por $Q R$ Code atende a determinação legal que versa sobre a obrigatoriedade de identificação da arborização municipal. A placa de identificação com o $Q R$ Code, fixada numa pequena base próxima à árvore, é lida pelo dispositivo móvel do usuário, retornando as informações da árvore no mapa. Essa solução segue o requisito legal que restringe a fixação de faixas, cartazes ou anúncio de qualquer natureza nas árvores, conforme 0 art. $1^{\circ}$, inciso VIII, do Decreto n4161 de 06 de outubro de 2010 (SETE LAGOAS, 2016).

Este trabalho analisou a arborização urbana quali-quantitativamente, tematizando dados coletados através de questionário de campo em um mapa. Contudo, diferentemente de Souza et al. (2011) que executam a mesma análise para a arborização viária nas ruas principais de Aracaju-SE, o protótipo de geovisualização da arborização viária patrimoniada foi disponibilizado na internet, permitindo o seu amplo acesso.

Por isso, o desenvolvimento do protótipo utilizou ferramentas simples como o Google My Maps, aplicativo gratuito e acessível, demonstrando a possibilidade de realizar o mapeamento mesmo com limitação de recursos financeiros. Desse modo, criou-se um produto útil, fornecendo ao usuário, simultaneamente, informações textuais, visuais e funcionalidades WebGIS como busca de pontos de interesse, visualização de imagens de satélite e melhor caminho entre pontos.

\section{Arborização local em síntese}

$\mathrm{Na}$ visita de campo se constatou que nenhum espécime possui risco imediato de queda, contudo se verificou a necessidade de intervenções corretivas, principalmente podas de manutenção. 
Além disso, foi observado que $14 \%$ dos espécimes apresentaram aspectos negativos relacionados à formação da copa, galhos, flores, sementes, crescimento do tronco, crescimento das raízes, pragas, insetos, fungos, doenças ou marcas de vandalismo. Essas observações indicam a necessidade de estudos técnicos complementares, mostrando o papel do protótipo como ferramenta de planejamento do poder público nas intervenções ou inspeções em campo.

O quadro geral da análise sobre a distribuição da arborização viária patrimoniada da Zona Z7 é apresentado na Tabela 3, sintetizando as informações obtidas em campo. Nessa tabela estão relacionadas 98 árvores que possuem leis ou decretos municipais específicos que as protegem, imunizando-as de corte. Destas $43 \%$ possuem altura superior a 10 metros, sendo 6 com CAP acima de 4,0 metros, tendo quatro árvores substituídas e uma suprimida.

Tabela 3. Frequência da arborização viária patrimoniada na área $Z 7$ da cidade de Sete Lagoas-MG Table 3. Heritage street tree frequency on $Z 7$ area of Sete Lagoas-MG

\begin{tabular}{l|l|c|c}
\hline Nome Científico & Nome popular & $\begin{array}{l}\text { Freq. } \\
\mathrm{n}^{\circ}\end{array}$ & $\begin{array}{l}\text { Freq. } \\
\%\end{array}$ \\
\hline Hura crepitans L. & Açacu & 1 & 1,02 \\
\hline Mauritia flexuosa L.f. & Buriti & 2 & 2,04 \\
\hline Ficus microcarpa & Ficus & 2 & 2,04 \\
\hline Ficus gomelleira Kunth \& C.D. Bouché & Gameleira & 2 & 2,04 \\
\hline Mangifera indica L. & Mangueira & 1 & 1,02 \\
\hline Licania tomentosa (Benth.) Fritsch & Oiti & 2 & 2,04 \\
\hline Caesalpinia echinata Lam. & Pau-brasil & 6 & 6,12 \\
\hline Caesalpinia ferrea Mart. ex. Tul var. leiostachya Benth & Pau-ferro & 2 & 2,04 \\
\hline Roystonea regia (Kunth) O.F. Cook & Palmeira-real & 78 & 79,60 \\
\hline Lecythis pisonis Cambess & Sapucaia & 1 & 1,02 \\
\hline Tipuana tipu (Benth) Kuntze & Tipuana & 1 & 1,02 \\
\hline Total & & 98 & $\mathbf{1 0 0}$ \\
\hline
\end{tabular}

De modo geral, ao longo da Zona Z7 observaram-se trechos viários com total ausência de arborização viária patrimoniada, seja pela presença de aspectos impeditivos relativos à infraestrutura urbana, seja pela falta de recomposição das supressões. A existência de rede elétrica é outro fator complicador, pois se observou que podas sucessivas alteraram a harmonia estética e a copa de algumas árvores. Por outro lado, têm-se áreas com expressiva contingência de espécimes arbóreos, bem como existem, em todos os casos, espaço para infiltração e crescimento de raízes.

A arborização viária patrimoniada da Zona Z7 de Sete Lagoas-MG foi estimada, conforme parâmetros formulados por Kane e Kirwan (2009), como um patrimônio coletivo no valor de US\$2.767,40/ano. Ainda que os parâmetros, medidos em dólares, retratem o contexto norte americano, os benefícios da arborização urbana indicados por Kane e Kirwan (2009) são uma realidade comum à arborização urbana. Pois conforme, Roy, Byrne e Pickering (2012) a 
arborização urbana pode ser mensurada financeiramente para qualquer tipo de clima, exaltando assim a necessidade da sua valorização e proteção pela coletividade e pelo poder público.

Por exemplo, Martini et al. (2016) quantificaram a amenização do microclima, avaliando a contribuição da arborização urbana no conforto térmico do espaço público da cidade de Campo Grande-MS. Nessa quantificação, os autores apontaram as árvores capazes de amenizar o microclima urbano, melhorando o conforto térmico pela amenização da radiação solar. Para isso, realizaram medições de temperatura em doze árvores e em seu entorno, obtendo o conforto térmico por cada árvore.

A caracterização da arborização urbana de Martini et al. (2016) e Souza et al. (2011) não foi disponibilizada na internet, nem os dados mostrados por Saarinen et al. (2014) são passiveis de atualização pelo próprio cidadão ou pelo gestor público, ainda que Saarinen et al. (2014) afirmem que a arborização urbana tenha se transformado em um serviço ambiental e social relevante. No protótipo disponibilizado existe uma ferramenta de geocolaboração, permitindo a troca de conhecimentos e informações através do envio de mensagens de feedback entre o administrador do protótipo e a população. O canal de geocolaboração para feedbacks é apresentado na figura 7.

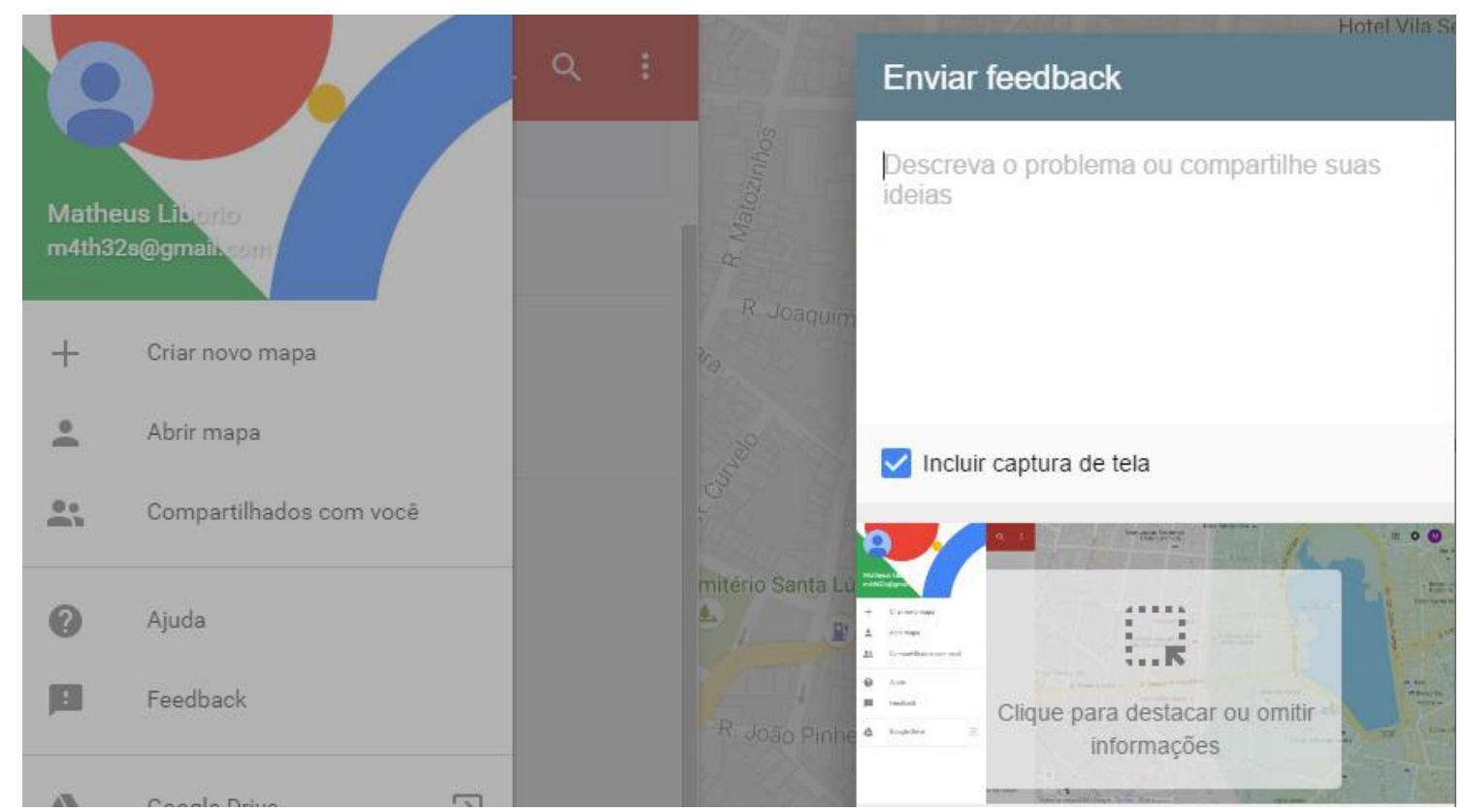

Figura 7. Canal de geocolaboração entre o usuário e o administrador do protótipo Figure 7. Geo collaboration with prototype administrator

Konijnendijk et al. (2006) exaltaram os benefícios do uso da ciência e da tecnologia na gestão das árvores para a sociedade, bem como Lorenzi et al. (2014) exaltaram a utilização do $Q R$ Code e da geovisualização no processo de difusão de mapas. 
Assim como no protótipo de geovisualização da arborização viária patrimoniada da Zona Z7, Bowie, Millward e Bhagat (2014) mostraram as vantagens do mapeamento interativo para a gestão árvores urbanas e os benefícios do uso de ferramentas simples e gratuitas como o Google Fusion Tables e as tecnologias API do Google Maps.

Por fim, Lorenzi et al. (2014) mostraram como melhorar serviços de governo através de $Q R$ Code em plataformas móveis e disseminar informações de forma ampla e interativa. Desse modo, este trabalho abordou a geovisualização da arborização urbana viária patrimoniada, apresentando um protótipo inovador, de acesso público, integrando informações de forma interativa e associada a códigos de identificação ou $Q R$ Codes.

\section{CONCLUSÕES}

Este artigo apresentou um protótipo de geovisualização que permite visualizar e difundir a arborização viária patrimoniada da região central de Sete Lagoas-MG, contribuindo para a gestão do patrimônio da arborização através do amplo e irrestrito acesso à informação, atendendo totalmente o objetivo da pesquisa.

Os resultados mostraram que os benefícios da arborização urbana podem ser estimados financeiramente, e que os métodos existentes precisam ser adaptados para 0 contexto brasileiro. $O$ uso do $Q R$ Code na identificação da arborização também se mostrou eficiente, seja pelo repositório de informações que são transmitidas ao usuário, seja por atender às restrições legais relacionadas à fixação de faixas e afins nas árvores. O protótipo produzido é uma ferramenta aberta, de baixo custo, com funcionalidades úteis e de fácil uso.

As informações e as ferramentas do protótipo mostraram-se eficazes para difundir conhecimentos sobre a arborização viária patrimoniada, e consequentemente favorecer ações de preservação pelos gestores públicos, bem como sua fruição pela população. Esta pesquisa apresentou um método que contribui para que outros municípios desenvolvam ferramentas de gestão da arborização urbana de baixo custo para. Para aumentar a relevância da pesquisa, um trabalho futuro seria mapear toda a arborização urbana de Sete Lagoas-MG e adaptar o método de valoração das árvores para o contexto brasileiro.

\section{REFERÊNCIAS}

BASSO, J. M.; CORRÊA, R. S. Arborização urbana e qualificação da paisagem. Paisagem e Ambiente, São Paulo, n. 34, p. 129-148, 2014.

BATISTA, D. L.; BARBOSA, R. I. Agro biodiversidade urbana: composição florística, riqueza e diversidade de plantas nos quintais de Boa Vista, Roraima. Revista Brasileira de Agroecologia, Porto Alegre, v. 9, n. 2, p. 130-150, 2014. 
BENATTI, D. P.; TONELLO, K. C.; ADRIANO JÚNIOR, F. C.; SANTANA DA SILVA, J. M.; OLIVEIRA, I. R. de; ROLIM, E. N.; FERRAZ, D. L. Inventory of the tree planting in Salto de Pirapora-SP. Revista Árvore, Viçosa, v. 36, n. 5, p. 887-894, 2012.

BONAMETTI, J, H. Arborização urbana. Terra e Cultura, 2001, n 36, 51-55, 2001.

BOWIE, G. D.; MILLWARD, A. A.; BHAGAT, N. N. Interactive mapping of urban tree benefits using Google Fusion Tables and API technologies. Urban Forestry \& Urban Greening, Davis, v. 13, n. 4, p. 742-755, 2014.

CHOW, T. E. The potential of maps APIs for internet GIS applications. Transactions in GIS, Chichester, v. 12, n. 2, p. 179-191, 2008.

GASTON, K. J.; ÁVILA-JIMÉNEZ, M. L.; EDMONDSON, J. L. Review: Managing urban ecosystems for goods and services. Journal of Applied Ecology, London, v. 50, n. 4, p. 830840, 2013.

GRANDE ORTIZ, M.; AYUGA TÉLLEZ, E.; CONTATO-CAROL, M. L. Methods of tree appraisal: a review of their features and application possibilities. Arboriculture \& Urban Forestry, v. 38, n. 4, p. 130-140, 2012.

IBGE, Instituto Brasileiro de Geografia e Estatística. Canal Cidades. Disponível em: <http://www.cidades.ibge.gov.br/xtras/home.php. Acesso em:_05 fev. 2016.

KANE, B.; KIRWAN, J. L. Value, Benefit, and Costs of Urban Trees. Virginia Cooperative Extension, 420-181, 2009.

KIRNBAUER, M. C., KENNEY, W. A., CHURCHILL, C. J., BAETZ, B. W. A prototype decision support system for sustainable urban tree planting programs. Urban Forestry \& Urban Greening, Davis, v. 8, n. 1, p. 3-19, 2009.

KONIJNENDIJK, C. C. A.; RICARD, R. M. B; KENNEY, A. C; RANDRUP, T. B. D. Defining urban forestry - A comparative perspective of North America and Europe. Urban Forestry and Urban Greening, Davis, v. 4, n. 3-4, p. 93-103, 2006.

LAUDARES, S. Geotecnologia ao Alcance de Todos. 1 ed. Curitiba - PR: Editora Appris, 2014. $83 \mathrm{p}$.

LORENZI, D.; VAIDYA, J.; CHUN, S.; SHAFIQ, B.; ATLURI, V. Enhancing the government service experience through $Q R$ codes on mobile platforms. Government Information Quarterly, Philadelphia, v. 31, n. 1, p. 6-16, 2014.

MARTINI, A.; BIONDI, D.; BATISTA, A. C.; DA SILVA FILHO, D. F. Microclima em diferentes tipologias de floresta urbana. Revista da Sociedade Brasileira de Arborização Urbana, Piracicaba, v. 10, n. 4, p. 12-22, 2016.

MEIRA, G. R. N.; TEIXEIRA, G. G. M.; VENTURIN, P. R. F.; GOTTSTEIN, P., CAXAMBU, M. G. Avaliação quali-quantitativa de espécies arbóreas no perímetro urbano da cidade de Corumbataí do Sul-PR. Revista da Sociedade Brasileira de Arborização Urbana, Piracicaba, v. 10, n. 4, p. 36-49, 2016.

ORDÓÑEZ, C.; DUINKER, P. N. Urban forest values of the citizenry in three Colombian cities. Society \& Natural Resources: An International Journal, Philadelphia, v. 27, n. 8, p. 834-849, 2014. 
PATAKI, D. E.; MCCARTHY, H. R.; LITVAK, E.; PINCETL, S. Transpiration of urban forests in the Los Angeles metropolitan area. Ecological Applications, Ithaca, v. 21, n.3, 661-677, 2011.

QUISSINDO, I. A. B.; OCONOR, E. F.; LUNA, D. P. Avaliação da vegetação arbórea nas principais ruas da cidade do Huambo-Angola. Revista da Sociedade Brasileira de Arborização Urbana, Piracicaba, v. 1, n. 1, p.43-54, 2016.

ROY, S.; BYRNE, J.; PICKERING, C. A systematic quantitative review of urban tree benefits, costs, and assessment methods across cities in different climatic zones. Urban Forestry \& Urban Greening, Davis, v. 11, n. 4, p. 351-363, 2012.

SAARINEN, N.; VASTARANTA, M.; KANKARE, V.; TANHUANPÄÄ, T.; HOLOPAINEN, M.; HYYPPÄ, J.; HYYPPÄ, H. Urban-tree-attribute update using multisource single-tree inventory. Forests, Basel, v. 5, n. 5, p. 1032-1052, 2014.

SEAMANS, G. S. Mainstreaming the environmental benefits of street trees. Urban Forestry \& Urban Greening, Davis, v. 12, n. 1, p. 2-11, 2013.

SETE LAGOAS, P. M. Legislação Municipal de Sete Lagoas - MG. Disponível em: $<$ https://leismunicipais.com.br/prefeitura/mg/setelagoas>. Acesso em: 05 fev. 2016.

SOUZA, A. L. de; FERREIRA, R. A.; MELLO, A. A. de; PlÁCIDO, D. da R.; SANTOS, C. Z. A. dos; GRAÇA, D. A. S. da; ALMEIDA JÚNIOR, P. P. de; BARRETTO, S. S. B.; DANTAS, J. D. de M.; PAULA, J. W. A. de; SILVA, T. L. da; GOMES, L. P. S. Diagnóstico quantitativo e qualitativo da arborização das praças de Aracaju. Revista Árvore, Viçosa, v. 35, n. 6, p. 12531263, 2011.

YOUNG, R. F. Managing municipal green space for ecosystem services. Urban Forestry \& Urban Greening, Davis, v.9 n.4, 313-321, 2010. 